\section{Evidence-Based Practices in The Public School: The Role of Preservice Teacher Training}

Stacy Lauderdale-Littin ${ }^{\mathrm{a},{ }^{\star},}$, Mary Brennan ${ }^{\mathrm{a}}$

\author{
Received: 18 September 2017 \\ Revised: 11 October 2017 \\ Accepted: 28 November 2017 \\ ISSN: 1307-9298 \\ Copyright (C) IEJEE \\ www.iejee.com
}

DOI: 10.26822/iejee.2018336195

\begin{abstract}
In the last twenty years, the educational system has seen a drastic increase in the number of individuals served under the category of autism spectrum disorder (ASD); which has led to an emphasis on ways in which to meet the needs of this multifaceted group of students. Although evidence-based practices (EBPs) have been identified for this population, research suggests teachers report having only moderate levels of confidence in their ability to implement these EBPs. The purpose of this review of the literature is to identify ways in which public school teachers determine the interventions used to meet the IEP goals of students with ASD, the efficacy of the chosen interventions, and the ways in which teacher preparation can be improved to ensure teachers are better able to identify and implement appropriate EBPs. Findings suggest an emphasis on coursework, and fieldwork specifically related to meeting the needs of students with ASD, should be addressed in preservice teacher training programs.
\end{abstract}

Keywords: Autism Spectrum Disorder; evidence-based practices; preservice teacher training.

\section{Introduction}

Over the last two decades in the United States' educational system, there has been a drastic increase in the number of students classified under the category of Autism Spectrum Disorder (ASD). Under the Individuals with Disabilities Education Improvement Act (IDEIA, 2004), ASD is defined as a developmental disorder, typically evident before the age of 3, which impacts verbal and non-verbal communication and social interaction. Additional characteristics that adversely affect the child's educational performance are resistance to change in routine, engaging in restrictive and repetitive behavior, and unusual sensory response. The past 20 years has seen an increase in the prevalence of ASD, which has reached 1 in 68 nationally (CDC; Center for Disease Control and Prevention, 2016). In addition, the United States Department of Education has reported similar findings with an increase in individuals eligible for services under ASD from 3.29\% percent of the special education population in 2005 to $7.02 \%$ percent in 2011. In New Jersey, the CDC (2016) estimates 1 in 45 children (or 21.9 per 1,000 8-year-olds) was identified with ASD. This estimate is higher than the average number of children identified with ASD in all areas of the United States where CDC tracks ASD. With this reported rise in autism prevalence within the school system, the need for research to become more focused on ways in which to meet the various needs of this diverse population of students has also intensified; especially in light of findings indicating that students with ASD are struggling in areas related to academics, social skills, communication, behavior, and selfdetermination (Carter Lane, Cooney, Weir, Moss, \& Machalicek, 2013).

One area related to meeting student need is practitioner implementation of evidence-based practices (EBPs) within the school system. Wong et al. (2015) identified 27 EBPs from the literature (See table 1) that could be utilized to teach various skills and concepts to individuals with ASD. Although these 27 EBPs have been clearly identified, integration of these practices into the school system have been minimal (lovannone, Dunlap, Huber, \& Kincaid, 2003). This is educationally problematic because research has indicated that the utilization of EBPs has led to significant improvements in skill acquisition and behavior reduction when these practices are implemented with fidelity (Simpson, McKee, Teeter, \& Beytien, 2007). Thus, student educational progress is negatively impacted when these research-based practices are not utilized within student programming.

The focus of this review is to delineate ways in which preservice teacher training can support the implementation of EBPs, with fidelity, in the school setting. The review further seeks to address information pertaining to teachers use of evidence-based practices in the classroom and ways in which preservice teacher training programs can increase teacher preparedness to better meet the needs of students with ASD. 
Table 1. Wong et al. (2015) 27 Evidence-based Practices

\begin{tabular}{llll}
\hline 1. & Antecedent based-interventions & 15. & Prompting \\
\hline 2. & Cognitive behavioral therapy & 16. & Reinforcement \\
\hline 3. & $\begin{array}{l}\text { Differential reinforcement of alternative, } \\
\text { incompatible, or other behavior }\end{array}$ & 17. & Response interruption/redirection \\
\hline 4. & Discrete trial teaching & 18. & Scripting \\
\hline 5. & Exercise & 19. & Self-management \\
\hline 6. & Extinction & 20. & Social narratives \\
\hline 7. & Functional behavior assessment & 21. & Social skills training \\
\hline 8. & Functional communication training & 22. & Structured play group \\
\hline 9. & Modeling & 23. & Task analysis \\
\hline 10. & Naturalistic intervention & 24. & $\begin{array}{l}\text { Technology-aided instruction and } \\
\text { intervention }\end{array}$ \\
\hline 11. & Parent-implemented intervention & 25. & Time delay \\
\hline 12. & Peer-mediated instruction and intervention & 26. & Video modeling \\
\hline 13. & Picture exchange communication systems (PECS) & 27. & Visual supports \\
\hline 14. & Pivotal response training & & \\
\hline
\end{tabular}

\section{Teacher knowledge of autism and evidence-based practices}

Evidence-based practices are interventions that have considerable corroboration in the literature supporting positive outcomes for learners with ASD. The currently identified 27-EBPs can be divided into four categories including: interventions based on the fundamental science of applied behavior analysis (ABA), interventions in which the way they are delivered define the practice, interventions based on assessment and analytic techniques, and behavioral practices that, when used systematically, can be replicated (Wong et al., 2015). These EBPs are also divided by age spans (0-5, 6-14, 15-22); which identify the age in which there is support for their use, as well as, skills that can be addressed utilizing each EBP (ie. social, communication, behavior, play, joint attention, cognitive, school readiness, academic, motor, adaptive, vocational, and mental health). If one looks at the legislation for IDEIA (2004) and No Child Left Behind (NCLB, 2001), it specifically states that teachers are required to utilize scientifically based strategies to meet the needs of students with disabilities. However, research has indicated educators do not consistently use EBPs in the classroom (Hess, Morrier, Heflin, \& Ivey, 2008). In a study by Morrier, Hess, and Heflin (2010), fewer than 5\% of teachers reported using EBPs for students with ASD. This means that even when teachers did report using EBPs, they also indicated using ineffective practices, and often practices with little empirical support. In fact, teachers have reported using ineffective strategies as frequently as those with a strong research base (Burns \& Ysseldyke, 2009).

After further examination, it becomes clear that the successful education of students with ASD is dependent on the teaching skills of the educators working with them (Leblanc, Ricciardi, \& Luiselli, 2005). When discussing teacher preparedness to teach students with ASD, one of the more complex issues facing the field of education, is training teachers to identify and implement EBPs for this population of students (Simpson, de Boer-Ott, \& SmithMyles, 2003). Training future teachers in this area will provide them with the skills necessary to make informed educational decisions. Because students with ASD are a heterogeneous group, and have unique educational needs, this will be a more challenging task for teacher education preparation programs (McGee \& Morrier, 2005; Simpson \& Myles, 1998). Although potentially difficult, providing training in this specific set of skills is imperative because the classroom is where students with ASD receive most of their treatment (Sindelar, Brownell, \& Billingsley, 2010). In order for the treatment to be operative, teachers need to be able to implement the most effective interventions. The question that is raised for teacher education preparation programs is how to address the overall deficit in teacher understanding of EBPs, acceptance of these practices, and use of components of programming that are essential for student success (Callahan, Henson, \& Cowan, 2008).

As one further investigates this dilemma, several potential reasons why scientifically validated interventions are not utilized in the classroom emerge. One reason could be teacher lack of understanding of the core deficits associated with autism and/or outdated beliefs about the disability (Al-Sharbati et al., 2015). Whaley (2002) found that some teachers did have good general knowledge about ASD, but lacked training related to research based methods that should be used in the classroom. This could lead to these practices being used at low levels, in part, due to not only a deficiency in research based methods training in general, but also a lack of knowledge about which interventions have been identified as evidence-based. Further, when current EBPs are able to be identified, there is the inability to implement these interventions with fidelity. Teachers sometimes view these strategies as not fitting with the interventions already in use within the classroom (Lang et al., 2010), leading to a lack of implementation.

Additional factors that influence application of EBPs include lack of professional development and interaction with a variety of learners (Odom, Boyd, Hall, \& Hume, 2010). Public school educators currently report receiving inadequate training in EBPs and not feeling they have the ability to meet the needs of this group of students (Jennett, Harris, \& Mesibov, 2003). They also report the training they receive is most frequently provided in professional development one day workshops, through trial and error 
while working hands on with students with ASD, or by teaching themselves (Morrier, Hess, \& Heflin, 2010). Educators teaching themselves, and having no formal training, typically leads to a lack of implementation fidelity. It can also lead to disregarding core components of specific interventions necessary to correctly utilize these practices (Odom, 2009). There is also evidence to indicate that the most common forms of professional development, including one-day workshops, have limited impact on practitioner ability to implement these interventions (Hall, Grundon, Pope, \& Romero, 2010). In addition, once teachers begin working in the public-school system, constraints such as budget and personnel have been identified as road blocks to creating a comprehensive autism program (Callahan et al., 2008). Districts have also sited lack of access to qualified individuals, who specialize in working with students with ASD, to provide in-service teacher training (Lang et al., 2010). All of these points emphasize the need for follow up within the classroom to ensure interventions are being implemented with fidelity as an essential component of effective teacher training (Simosen, Myers, \& DeLuca, 2013). One result of public schools being unable to provide the necessary teacher training once they are in the field, due to the professional development limitations and budget constraints, is lack of additional training specific to students with ASD once preservice teachers enter the field. Therefore, there needs to be a shift in the model for preservice teacher training programs to focus more on preparation of teachers to work with students with ASD, and the use of EBPs, to bridge the gap between research focused on identification of EBPs and positive student outcomes in the classroom (Greenwood \& Maheady, 1997).

\section{Preservice teacher training}

The National Research Council (2001) reported that most educators graduate from preservice teacher training programs receiving minimal training in evidence-based research practices (i.e., methodologies grounded in ABA) for students diagnosed with autism. This is one of the most needed areas of improvement within higher education. Credential programs training special education teachers often do not teach educators how to meet the needs of students with ASD (Holdheide \& Reschly, 2008) because they focus on special education practices that can be used for a broader population, and not specifically for individuals with autism (Williams, Fan, \& Goodman, 2010). Special education licensure requirements are also not consistent from state to state leading to varying levels of knowledge for teacher candidates in the area related to meeting the needs of students with autism. This leaves educators unprepared to successfully meet the needs of students with ASD (Suhrheinrich, 2011). This lack of preparation also places teachers at a disadvantage because all teachers, in special and general education, will most likely have a student with ASD in their classroom and they need to be well versed in strategies to meet their unique needs (Loiacono \& Valenti, 2010).

Even though the field, as a whole, is not meeting teacher needs related to training in ASD, there has been an increase in the development of teacher training programs, specifically related to teaching students with ASD. Barnhill,
Polloway, and Sumutka (2011) conducted a survey of 87 institutes of higher education, across 43 states, in order to determine the number of teacher training programs focused on meeting the needs of students with ASD, the specific topics of focus within these programs, and the emphasis of autism specific coursework. They found that there was an increase in the development, and application, of teacher preparation programs focusing on ASD, however, the topics covered in these programs vary greatly, in part, because there are few states providing guidance as to the requirements for licensure. Many states are providing non-categorical certification and training with no explicit emphasis or licensure provided for specific disabilities (Scheuermann, Webber, Boutot, \& Goodwin, 2003). These findings suggest the need for consistency between programs in order to prepare teachers to work with students with ASD upon graduation from teacher preparation programs. This preparation can be accomplished with a combination of university coursework and hands-on training in the clinical placements working with students with ASD.

Preservice teacher training has a direct impact on a teacher's ability to meet the needs of students in the classroom. In order to more readily prepare teachers to work with students with ASD, colleges and universities can replace 1-2 generic education courses with an autism specific course or two. This change would effectively increase teacher knowledge of the disorder and ways in which to better meet student needs (Scheuermann et al., 2003). The research of Callahan, Henson, and Cowan (2008) suggests that the development of an ideal autism program includes training preservice educators in creating individualized programs to address the needs of each student, collecting data in order to make data based decisions for skill acquisition and behavior reduction programming, utilization of EBPs, a focus on maintaining and generalizing skills, and collaboration with a multidisciplinary team. These skills can be taught by using effective methods already in place, such as the application of knowledge of EBPs with individuals with autism, and submission of video with candidates demonstrating the use of an EBP that can be reviewed and conferenced with a mentor (Hall, 2014). The feedback provided from a mentor, while reviewing the video, is an integral component required for teachers to understand how to implement EBPs with fidelity. Research also supports the idea that undergraduate candidates be required to take course work related to ABA, as many EBPs are based on these scientific principles (Wong et al., 2015). The findings of Loiacono and Valenti (2010) further suggest that teachers should gain knowledge related to ABA throughout their coursework because these intervention methodologies are not only beneficial when working with students with ASD, but also when working with students with other disabilities as well. These suggested changes in teacher preparation training programs would provide a cadre of trained professionals to enter the work force knowledgeable of how best to use, with fidelity, the EBPs in classrooms with students with ASD.

Looking at the identified needs within the public school, when special education directors were asked to identify essential skills teachers would need to work with students 
with ASD, they included knowledge of characteristics of autism, behavior management, and knowledge as to how to develop communication skills (Hart \& Malian, 2013). Training in the field also needs to be provided on all aspects of EBPs being implemented, including preparing and concluding sessions, and not just focus on the technical aspects of the intervention (Downs \& Downs, 2012). In addition, teachers should learn how to make instructional decisions that lead to student skill acquisition and behavior reduction (Vince Garland, Holden, \& Garland, 2016). These topics could be addressed within autism specific coursework at the undergraduate level providing teachers with an array of strategies which can be used in the classroom, in addition to, field experiences working with students with ASD to apply this content knowledge.

McGee and Morrier (2005) recommended a combination of education in fundamental content related to the diverse needs of students with ASD and working directly with students with ASD to apply the knowledge learned in the classroom. Individuals who received training in effective interventions for students with ASD, in addition to, engaging in fieldwork experiences working with students with ASD had higher levels of knowledge than individuals who did not have these experiences (Sanz-Cervera, Fernandez-Andres, Pastor-Cerezuela, \& Tarraga-Minguez, 2017). Thus, coursework pertaining to the utilization of EBPs, accompanied with the opportunity to work with students with autism to implement these practices, is essential in order to prepare pre-service teachers to successfully work with this population.

When training teachers in the university classroom, and then assisting them to successfully implement these practices in the school setting with students with autism, Ruef, Nefdt, Openden, Elmensdorp, Harris, and Robinson (2009) utilized didactic training, followed by videotaped sessions and weekly feedback, in a collaborative school and university model. This model included individuals working directly with students in the public-school, videotaping themselves, and meeting with university graduate students, who had received training in EBPs, to obtain feedback related to implementation. The ability to work hands-on with students with ASD reiterated information provided within university coursework including identifying from the literature, and implementing, research-based strategies, and collecting data to monitor progress and make data based decisions.

In addition to providing feedback from videos, performance feedback has also been successful in training teachers to implement EBPs within the classroom (Fixsen, Blase, Naoom, \& Wallace, 2009; McHugh \& Barlow, 2010; Suhrheinrich, 2011). Performance feedback includes an observation of the pre-service teacher implementing an intervention in an applied setting, followed by behavior specific feedback (Solomon, Klien, \& Politylo, 2012). The purpose of performance feedback is to increase treatment integrity, or the degree to which all core intervention components are implemented correctly (Noell, Witt, LaFleur, Mortenson, Ranier, \& LeVille, 2000). When Solomon et al. (2012) completed a meta-analysis related to the effectiveness of performance feedback, they found that there were significant behavioral changes noted regardless of setting, dependent variable, the delay between observation and feedback (immediate vs. next day), or intervention of focus when this method was used. They also found it was effective in all grade levels, from preschool to high school. These findings support the use of performance feedback as an easy-to use strategy, that increases teacher treatment integrity. This strategy could be incorporated in lieu of, or in addition to, video-based feedback in university training programs depending on the ability of the university to provide these services.

In addition to the need for university programs to become more involved in teacher training specific to ASD, Hart and Millian (2013) provided suggestions from qualitative data collected from special education directors focusing on the role of university preparation programs. Respondents indicated that higher education programs could support teacher preparedness by:

- Requiring general and special education teacher candidates to complete fieldwork, and take more courses focused on preparation for, working with students with ASD.

- Providing teacher candidates with specific training in management of problem behavior, determination, and implementation, of accommodations and modifications, and advocacy.

- Supporting practicing teachers once in the field by utilizing in class consultation, online, and webcasts.

Based on the suggestions from the literature as to the content which would be most beneficial to prepare preservice teachers to work with students with ASD, some recommendations for University undergraduate programs include the following: replace one or two generic education courses with autism specific coursework (Scheuermann et al., 2003) and require field experiences working directly with students with ASD (Sanz-Cervera et al., 2017). Within this coursework, address the unique needs and heterogeneous nature of students with ASD. There should also be an emphasis during courses on the principles of ABA and identification of EBPs (Loiacono, \& Valenti, 2010). This information is important to include as many of the current EBPs utilize the science of ABA and teachers need to be able to determine appropriate EBPs to meet student goals, as well as, have the ability to implement these interventions with fidelity. Knowledge of ABA will also provide important foundational knowledge necessary for teachers to meet these requirements.

In order to address the fieldwork component, preservice teachers should be required to observe model programs which effectively work with students with ASD. They should also work with students with ASD and implement EBPs (Hall, 2014). This can be accomplished by embracing competency training with performance feedback (Fixsen et al., 2009, McHugh \& Barlow, 2010; Suhrheinrich, 2011). The fieldwork component will lead to greater preservice teacher understanding as to how to utilize EBPs for student goal attainment. It will also assist in increasing treatment integrity of EBPs.

Although the information within this review is not all inclusive, information from the literature supports the 
need for more training specific to working with students with ASD for all preservice teachers. University coursework needs to provide foundational knowledge related to the core deficits associated with ASD, accommodations and modifications which can be used to support this population, ways in which to identify EBPs most effective in meeting the needs of these students, and knowledge on how to evaluate the effectiveness of such programming. Looking at it from the lens of a teacher, the learning of the above skills would provide the future teacher with knowledge of EBPs related to social skills, communication, behavior, play, joint attention, cognition, school readiness, academics, motor, adaptive, vocational, and mental health; for school age students (Wong et al., 2015). This instructional knowledge, and practical field experience, would incorporate all of the identified areas within this review and would prepare teachers to instruct students with ASD with methods that are research based, and implemented with fidelity. It will also allow teachers to be in accordance with the educational mandates established at the state and federal levels. Future classrooms will then provide opportunities for students with ASD to learn from teachers who are knowledgeable of the EBPs and can accommodate and modify in an educational setting to maximize the unique abilities of each child with ASD.

\section{References}

Al-Sharbati M. M., Al-Farsi Y. M., Ouhtit A., Waly M. I., AlShafaee M., Al-Farsi O., ... Al-Adawi S. (2015). Awareness about autism among school teachers in Oman: A crosssectional study. Autism, 19, 6-13

Barnhill, G. P., Polloway, E. A., \& Sumutka, B. M. (2011) A survey of personnel practices in autism spectrum disorders. Focus on Autism and Other Developmental Disabilities, 26, 75-86.

Burns, M. K., \& Ysseldyke, J. E. (2009). Reported prevalence of evidence-based instructional practices in special education, The Journal of Special Education, 43, 3-11.

Callahan, K., Henson, R. K., \& Cowan, A. K. (2008). Social validation of evidence-based practices in autism by parents, teachers, and administrators. Journal of Autism and Developmental Disorders, 38, 678-692.

Carter, E. W., Lane, K. L., Cooney, M., Weir, K., Moss, C. K., \& Machalicek, W. (2013). Parent assessments of selfdetermination importance and performance for students with autism or intellectual disability. American Journal on Intellectual and Developmental Disabilities, 88 , 16-31.

Center for Disease Control and Prevention. (2016). Prevalence and characteristics of autism

spectrum disorder among children aged 8-years: Autism and developmental disabilities

monitoring network, 11 sites, United States, 2012. Surveillance Summaries, 65, 1-23.

Downs, A., \& Downs, R. C. (2012). Training new instructors to implement discrete trials teaching strategies with children with autism in a community-based intervention program. Focus on Autism and Other Developmental Disabilities, 28, 212-221.

Fixsen, D. L., Blasé, K. A., Naoom, S. F., \& Wallace, F. (2009). Core implementation components. Research on Social Work Practice, 19 (5), 531-540.

Greenwood, C. R., \& Maheady, L. M. (1997). Measurable change in student performance: Forgotten standard for teacher preparation. Teacher Education and Special Education, 20, 265-275.

Hall, L. J. (2014). Sustaining evidence-based practices by graduated special educators of students with ASD: Creating a community of practice. Teacher Education and Special Education, 38, 28-43.

Hall, L. J., Grundon, G. S., Pope, C., \& Romero, A. B. (2010). Training paraprofessionals to use behavioral strategies when educating learners with autism spectrum disorders across environments. Behavioral Interventions, 25, 37-51.

Hart, J. E., \& Malian, I. (2013). A statewide survey of special education directors on teacher

preparation and licentiate in autism spectrum disorders: A model for university and state

collaboration. International Journal of Special Education, 28, 4-13.

Hess, K. L., Morrier, M. J., Heflin, L. J., \& Ivey, M. L. (2008). Autism Treatment Survey: Services received by children with autism spectrum disorders in public school classrooms. Journal of Autism and Developmental Disorders, 38, 961-971.

Holdheide, L. R., \& Reschly, D. J. (2008). Teacher preparation to deliver inclusive services to students with disabilities: TQ Connection Issue Paper. National Comprehensive Center for Teacher Quality, 1-28.

Individuals With Disabilities Education Improvement Act, Pub. L. No. 108-446. 118 Stat. 2647 (2004). Retrieved from http:// nichcy.org/wpcontent/uploads/docs/PL108- 446.pdf

Ivannone, R., Dunlap, G., Huber, H., \& Kincaid, D. (2003). Effective educational practices for students with autism spectrum. Focus on Autism and Other Developmental Disabilities, 18, 150-165.

Jennet, H. K., Harris, S. L., \& Mesibov, G. B. (2003). Commitment to philosophy, teacher efficacy, and burnout among teachers of children with autism. Journal of Autism and Developmental Disorders, 33, 583593.

Lang, R., O’Reilly, M. F., Sigafoos, J., Machalicek, W., Rispoli, M., Shogren, K., ... Hopkins, S. (2010). Review of teacher involvement in the applied intervention research for children with autism spectrum disorders. Education and Training in Autism and Developmental Disabilities, 45, 268-283.

Leblanc, M. P., Ricciardi, J. N., \& Luiselli, J. K. (2005). Improving discrete trial instruction by paraprofessional staff through an abbreviated performance feedback 
intervention. Education and Treatment of Children, 28, 76-82.

Loiacono, V., \& Valenti, V. (2010). General education teachers need to be prepared to co-teacher the increasing number of children with autism in inclusive settings. International Journal of Special Education, 25, 24-32.

McGee, G. G., \& Morrier, M. J. (2005). Preparation of autism specialists. In F. R. Volkmar, R.

Paul, A. Klin, \& D. Cohen (Eds.), Handbook of autism and pervasive developmental disorders: Vol. II. Assessment, interventions, and policy (pp. 1123-1160). New York, NY: Wiley.

McHugh, R. K. \& Barlow, D. H. (2010). The dissemination and implementation of evidence based psychological treatments: A review of current efforts. American Psychology, 65, 73-84.

Morrier, M. J., Hess, K. L., \& Heflin, L. J. (2012). Teacher training for implementation of teaching strategies for students with autism spectrum disorders. Teacher Education and Special Education, 34, 119-132.

National Research Council (2001). Division of Behavioral and Social Sciences and Education, Committee on Educational Interventions for Children with Autism (2001). Educating children with autism. Washington, DC: National Academy Press.

No Child Left Behind Act of 2001, Pub. L. No. 107-110, 115 Stat. 1425 (2001). Retrieved from http://www2.ed.gov/policy/elsec/leg/ esea02/index.html

Noell, G. H., Witt, J. C., LaFleur, L. H., Mortenson, B. P., Ranier, D. D., LeVelle, J. (2000). Increasing intervention implementation in general education following consultation: A comparison of two follow-up strategies. Journal of Applied Behavior Analysis, 33, 271-284.

Odom, S. L. (2009). The tie that binds: Evidence-based practice, implementation science and out-comes for children. Topics in Early Childhood Special Education, 29, 53-61.

Odom, S. L. Boyd, B. A., Hall, L. J., \& Hume, K. (2010). Evaluation of comprehensive treatment models for individuals with ASD. Journal of Autism and Developmental Disorders, 40, 425-436.

Ruef, M. B., Nefdt, N., Openden, D., Elmensdorp, S., Harris, K. C., \& Robinson, S. (2009). Learn by doing: A collaborative model for training teacher-candidate students in autism. Education and Training in Developmental Disabilities, 44, 343-355.

Sanz-Cervera, P., Fernandez-Andres, M., Pastor-Cerezuela, G., \& Tarraga-Minguez, R. (2017). Pre-service teachers' knowledge, misconceptions, and gaps about autism spectrum disorder. Teacher Education and Special Education, 40, 212-224.

Scheuermann, B., Webber, J., Boutot, E. A., \& Goodwin, M. (2003). Problems with personnel preparation in autism spectrum disorder. Focus on Autism and Other Developmental Disabilities, 18, 197-206.

Simonsen, B., Myers, D., \& DeLuca, C. (2010). Teaching teachers to use prompts, opportunities to respond, and specific praise. Teacher Education and Special Education, 33, 300-318.

Simpson, R. L., de Boer-Ott, S. R., \& Smith-Miles, B. (2003). Inclusion of learners with autism spectrum disorders in general education settings. Topics in Language Disorders, 23, 116-133.

Simpson, R. L., McKee, M., Teeter, D., \& Beytien, A. (2007). Evidence-based methods for children and youth with autism spectrum disorders: Stakeholder issues and perspectives. Exceptionality, 15, 203-217.

Simpson R. L., \& Myles, B. S. (1998). Educating children and youth with autism: Strategies for effective practice. Austin, TX: Pro-Ed.

Sindelar, P. T., Brownell, M. T., \& Billingsley, B. (2010). Special education teacher education research: Current status and future directions. Teacher Education and Special Education, 33, 8-24.

Solomon, B. G., Klein, S. A., \& Politylo, B. C. (2012). The effect of performance feedback on teachers' treatment integrity: A meta-analysis of the single-case literature. School Psychology Quarterly, 41, 160-175.

Suhrheinrich, J. (2011). Training teachers to use pivotal response training with children with autism: Coaching as a critical component. Teacher Education and Special Education, 43, 339-349.

U.S. Department of Education, Office of Special Education Programs, Data Analysis System. (2005). Children with disabilities receiving special education under Part $B$ of the Individuals With Disabilities Education Act, 2005.

U.S. Department of Education, Office of Special Education Programs, Data Analysis System. (2012). Children with disabilities receiving special education under Part $B$ of the Individuals With Disabilities Education Act, 2011. Retrieved from http://tadnet.public.tadnet.org/pages/712

Vince Garland, K. M., Holden, K., \& Garland, D. P. (2016). Individualized clinical coaching in the TLE TeachLivE lab: Enhancing fidelity of implementation of system of least prompts among novice teachers of students with autism. Teacher Education and Special Education, 39, 47 59.

Whaley, C. H. (2002). Special education teachers' and speech therapists' knowledge of autism spectrum disorder (unpublished doctoral dissertation). East Tennessee State University, TN, USA.

Williams, C. M., Fan, W., \& Goodman, G. (2011). Preliminary analysis of the "Survey of educator's knowledge and value of research-based practices for students with autism". Assessment for Effective Intervention, 36, 113130.

Wong, C., Odom, S. L., Hume, K. A., Cox, A. W., Fettig, A., Kucharczyk, S., ... Schultz, T. R. (2015). Evidence-based 
practices for children, youth, and young adults with autism spectrum disorder: A comprehensive review. Journal of Autism and Developmental Disorders, 45, 1951 1966. 
This page is intentionally left blank

www.iejee.com 